\title{
INCIDENCE OF OCULAR MOTILITY PROBLEMS FOLLOWING SCLERAL BUCKLING SURGERY
}

\author{
A. F. SPENCER, C. NEWTON and S. A. VERNON \\ Nottingham
}

\begin{abstract}
SUMMARY
The incidence and severity of extraocular muscle imbalance after conventional scleral buckling surgery was determined for 70 eyes of 68 patients with primary rhegmatogenous retinal detachment. Fifty-eight eyes had circumferential silicone explants, 10 eyes had radial sponges and 2 had both. Sixty-five per cent of eyes showed some restriction of ocular motility and $72 \%$ of patients had diplopia within their field of binocular single vision (BSV). The more extraocular muscles the explant was placed under, the more directions of gaze were likely to be restricted $(p=0.032)$. In $84 \%$ of eyes the restrictions could be related to the position of the explant. In $87 \%$ of patients their diplopia could also be related to the position of the explant. A second retinal detachment operation is more likely to cause restricted motility and more likely to cause diplopia within the expected field of $\operatorname{BSV}(p=0.0297)$.
\end{abstract}

Scleral buckling operations are known to cause postoperative strabismus in some patients. Previous studies ${ }^{1-18}$ have quoted an incidence ranging from $3 \%$ to $57 \%$ of cases. Many authors have been unable to demonstrate a relationship to the type or position of the explant. One prospective study ${ }^{19}$ demonstrates a higher incidence of muscle imbalance on detailed examination. Many of these studies include surgical techniques no longer in common use. This study evaluates the incidence and severity of extraocular muscle imbalance after retinal detachment surgery for primary rhegmatogenous detachment over a 2-year period.

\section{PATIENTS AND METHODS}

One hundred and thirteen patients were identified from theatre records who had had primary rhegmatogenous retinal detachment surgery between 1 January 1990 and 31 December 1991. Of these, 5 patients had moved away from the area, 18 had been secondary referrals from outside the catchment area, 3 further patients had died and 2

Correspondence to: Miss A. F. Spencer, FRCS, FRCOphth, Academic Unit of Ophthalmology, University Hospital, Queen's Medical Centre, Nottingham NG7 2UH, UK. had developed new ophthalmic problems which could affect ocular motility (namely dysthyroid eye disease and herpes zoster ophthalmicus). Two patients were untraceable on computer records. Of 83 remaining patients. invited to attend for full ocular motility examination 72 accepted. One was excluded from the study because of sympathetic ophthalmitis, and 3 more were excluded for incomplete data as the hospital records could not be found. The results from 68 patients (i.e. $82 \%$ of those invited) are therefore presented.

From the patients' records the following data was collected: (1) age, (2) sex, (3) previous history of strabismus, (4) history of previous ocular surgery, (5) best corrected visual acuity of affected eye and of the fellow eye as recorded, (6) whether the macula was detached, (7) tenotomy of any muscle at surgery, (8) location of the explant, (9) whether the explant was radial or circumferential, (10) size of explant, (11) whether diplopia had been a postoperative complaint and whether any treatment had been required.

The post-operative assessment was performed at least 7 months after surgery. Details of the retinal detachment surgical procedure that had been performed were not known at the time of this examination. The assessment included: (1) length of time from surgery to recall, (2) best corrected visual acuity, (3) cover-uncover and alternate cover tests in the primary position and cardinal positions of gaze to identify a heterophoria or heterotropia, (4) measurement of any deviations found by a prism cover test, (5) Maddox rod and Maddox wing, (6) if possible a Hess chart, particularly where there was a significant deviation, (7) stereopsis measured by Frisby plates and (8) a field of binocular single vision in any patient with diplopia, where acuity permitted.

\section{RESULTS}

\section{Clinical Characteristics}

Seventy eyes of 68 patients were examined. One patient had had bilateral surgery and 1 had scleral buckling surgery to the second eye within the study period. There were 48 male and 20 female patients. There was a previous 
history of amblyopia in 2 patients; these were the patients who had had surgery on both eyes. A third patient complained of diplopia pre-operatively; he developed a retinal detachment in his divergent right eye which was not amblyopic. The age range of the group studied was 10-84 years (mean 53 years).

\section{Previous Ocular Surgery}

Seven patients had had previous cataract extraction, 1 bilateral lens surgery had bilateral detachments. Therefore there were 62 phakic eyes $(88 \%), 3$ aphakic ( 2 intracapsular and 1 extracapsular) and 5 pseudophakic ( 4 posterior chamber and 1 anterior chamber intraocular lens). One eye had had a recent trabeculectomy, and 1 had had peripheral local retinal cryotherapy in the fellow eye at the same time as retinal detachment surgery in the first eye included in the study.

\section{Visual Acuity}

The macula was recorded to be detached in $39(56 \%)$ of 70 eyes at pre-operative assessment. In 1 case where the first operation was unsuccessful, the macula detached and the patient had further surgery.

Pre-operatively $48 \%$ of eyes had an acuity of $6 / 24$ or better; post-operatively $53 \%$ of eyes had an acuity of $6 / 12$ or better. This is detailed in Table I.

\section{Explant}

At review the type of explant used in 10 eyes was a radial plomb, 2 eyes had both radial and circumferential explants and 58 had a circumferential explant. Eight eyes had had the buckle removed by review: 6 circumferential (i.e. $10 \%$ of the circumferential) and 2 radial (i.e. $17 \%$ of the radial). In only 1 case was the buckle removed because the patient had diplopia. No eyes had been encircled and no tenotomy had been performed in any procedure. Further analysis is performed using these data.

Initially the type of explant used was a radial plomb alone in $12(17 \%)$ eyes. Three were removed at a second operation. In a further 3 eyes they were used at a second operation ( 1 in addition to a circumferential element; 1 was removed again at a third operation). A circumferential explant was used in $57(81 \%)$ eyes initially. It was changed to a different length or site or the type of explant was changed in 16 of 57 (28\%) eyes (in 1 a second explant was added to the original explant). A further 3 eyes had a circumferential explant after a radial plomb was removed. In 2 eyes the explant was removed and in 1 replaced again.

Table I. Pre-operative and post-operative visual acuities

\begin{tabular}{lcc}
\hline & \multicolumn{2}{c}{ No. of eyes } \\
\cline { 2 - 3 } Visual acuity & Pre-operative & Post-operative \\
\hline $6 / 6$ & 10 & 16 \\
$6 / 9$ to $6 / 12$ & 17 & 21 \\
$6 / 18$ to $6 / 24$ & 7 & 13 \\
$6 / 36$ to $6 / 60$ & 12 & 8 \\
$<6 / 60$ & 24 & 12 \\
\hline
\end{tabular}

One eye had both a radial $7 \mathrm{~mm}$ plomb and a circumferential Mira 276 explant initially.

The sizes of the silicone sponges used were $1 \times 3 \mathrm{~mm}$, $1 \times 4 \mathrm{~mm}, 9 \times 5 \mathrm{~mm}$ and $4 \times 7.5 \mathrm{~mm}$. The type of circumferential explant used was Mira silicone tyres: a 276 in 52 eyes, a 279 in 8 eyes and a 280 in 2 eyes. A $7.5 \mathrm{~mm}$ silicone sponge was used as a circumferential explant in 1 eye.

\section{Subsequent Surgery}

Overall there were 16 second operations in which a buckle or sponge was changed. This was combined with vitrectomy in 1 patient and with $\mathrm{C}_{3} \mathrm{~F}_{8}$ gas injection in another patient. A second procedure of $\mathrm{C}_{3} \mathrm{~F}_{8}$ injection alone was performed in 1 eye. Three patients had a third operation; a vitrectomy with silicone oil in 2 eyes and a vitrectomy with cataract extraction and intraocular lens in the third. Two eyes therefore needed silicone oil removal at a later date and 1 also had cataract extraction. One patient had an extracapsular cataract extraction and intraocular lens in the fellow eye prior to review.

\section{Time to Review}

All the patients were reviewed at least 9 months after initial surgery, when it was assumed that any temporary muscle imbalance would have settled and any ocular motility abnormality demonstrated would be permanent. The range of time to review was 9-32 months, median 22 months (mean $20.1 \pm 6.9$ months).

\section{Ocular Motility Examination}

On ductions, considering elevation, depression, abduction and adduction as the main positions of gaze, there was no restriction in 33 eyes. Restriction occurred in one position of gaze in 14 eyes, two positions in 15 eyes, three positions in 7 eyes and all four positions in 1 eye. Hess chart evaluation revealed some additional motility defects, i.e. a further 8 eyes showed some restrictions. Table II details the restriction in positions of gaze, by duction testing and Hess chart, in comparison with the number of muscles under which the explant was positioned. The more muscles the explant was under, the more directions of gaze were likely to be restricted. Chi-squared analysis shows this to be significant $(p=0.032)$. The buckle was under the superior rectus in 37 eyes, medial rectus in 18 eyes, lateral rectus in 39 eyes and inferior rectus in 26 eyes.

Table II. The number of positions of gaze in which a restriction was demonstrated in relation to the number of muscles under which the explant was placed

\begin{tabular}{lrrrrrr}
\hline \multirow{2}{*}{$\begin{array}{l}\text { No. of } \\
\text { muscles }\end{array}$} & \multicolumn{2}{l}{ No. of positions of gaze showing restriction } & \\
\cline { 2 - 5 } & 0 & 1 & 2 & 3 & 4 & Total \\
\hline 0 & 6 & 1 & 3 & 0 & 0 & 10 \\
1 & 5 & 3 & 7 & 2 & 0 & 17 \\
2 & 13 & 10 & 7 & 2 & 0 & 32 \\
3 & 0 & 3 & 1 & 2 & 0 & 6 \\
4 & 1 & 1 & 1 & 1 & 1 & 5 \\
Total & 25 & 18 & 19 & 7 & 1 & 70 \\
\hline
\end{tabular}


Table III. The direction in which a restriction of motility was noted in relation to the position of the explant

\begin{tabular}{lccc}
\hline $\begin{array}{l}\text { Restrictions of } \\
\text { gaze }\end{array}$ & $\begin{array}{c}\text { Single } \\
\text { operation }\end{array}$ & $\begin{array}{c}\text { Explant } \\
\text { removed before } \\
\text { review }\end{array}$ & $\begin{array}{c}\text { Explant } \\
\text { changed/ } \\
\text { further surgery }\end{array}$ \\
\hline $\begin{array}{l}\text { Away from explant } \\
\text { Towards explant }\end{array}$ & 11 & 2 & 9 \\
Away + towards & 7 & & 3 \\
All directions & 1 & & 3 \\
Unrelated to explant & 1 & 4 & 1 \\
None & 4 & 6 & 3 \\
Totals & 16 & & 5 \\
\hline
\end{tabular}

Consequently the buckle was more likely to be in the supero-temporal quadrant.

The restrictions can be directly related to the position of the explant in $84 \%$ of eyes $(38 / 45)$, i.e. to a muscle or muscles under which the explant passed, or in 2 eyes to the position of the radial sponge. This is detailed in Table III. Three eyes had restriction in the direction of the oblique muscles and these were found to lie under the explant in 2 out of the 3 cases.

Diplopia within the expected field of binocular single vision (BSV) can also be related to the explant in $87 \%$ of patients (40/46), including those with diplopia due to a large, i .e. $360^{\circ}$, explant. This is detailed in Table IV. In 5 patients this appeared to be related to the oblique muscles; in only 1 was this not explained by the position of the explant. Eight of 12 patients with a visual acuity of less than 6/60 could perform a field of BSV. Only 4 patients with very reduced central acuity and apparently severely restricted visual field were unable to co-operate with this test.

The Maddox rod was used to demonstrate vertical muscle imbalance. A deviation of 2-5 dioptres was found in 19 of $60(32 \%)$ patients who could perform the test and 4 of $60(7 \%)$ measured $>5$ dioptres. One patient also had a manifest hypertropia. Therefore in total 24 of $60(40 \%)$ had a significant vertical muscle imbalance.

Eight patients demonstrated an exotropia post-operatively (only 1 had an amblyopic eye), 2 an exophoria which became manifest for near vision, 1 an esotropia with abnormal head posture and 1 a hypertropia and exo-

Table IV. The direction in which diplopia was noted in relation to the position of the explant

\begin{tabular}{lccc}
\hline Diplopia & $\begin{array}{c}\text { Single } \\
\text { operation }\end{array}$ & $\begin{array}{c}\text { Explant } \\
\text { removed before } \\
\text { review }\end{array}$ & $\begin{array}{c}\text { Explant } \\
\text { changed/ } \\
\text { further surgery }\end{array}$ \\
\hline Away from explant & 7 & 1 & 5 \\
Towards explant & 12 & 1 & 5 \\
Away + towards & 0 & 1 & 1 \\
One or two directions & 1 & 0 & 2 \\
$\quad \begin{array}{l}\quad 360^{\circ} \text { explant) } \\
\text { All directions }\end{array}$ & 0 & 0 & 1 \\
$\quad\left(360^{\circ}\right.$ explant) & & & 2 \\
Unrelated to explant & 3 & 1 & 2 \\
Primary position & 1 & 0 & 2 \\
None & 14 & 2 & 3 \\
None, as poor VA & 1 & 0 & 23 \\
Totals & 39 & 6 & \\
\hline
\end{tabular}

tropia (but this patient had had a divergent squint preoperatively). Therefore 10 of 68 (15\%) had acquired a manifest squint following surgery.

\section{Recorded Diplopia}

From the records only 8 of 68 (12\%) patients had complained of diplopia, 3 of whom had radial plombs and 5 circumferential explants. Six had been treated with prisms and $1 \mathrm{had}$ had removal of a radial sponge from under the inferior rectus muscle. Removal of the plomb in this patient did not improve her symptoms and she had strabismus surgery, with only temporary improvement before fibrosis caused further problems. She was referred for botulinum toxin injection. Two patients had no treatment recorded in the notes; 1 of these had poor vision and the other had had prisms incorporated into spectacles prescribed by his optometrist. On review not all the other patients were asymptomatic.

\section{Macular Involvement}

Of 62 patients with unilateral detachment who could perform a field of BSV on review, 24 of 27 'macula on' detachments had diplopia somewhere in their field of expected BSV post-operatively compared with 22 of 35 'macula off' detachments. This difference is significant on chi-squared analysis $(p=0.0424)$. There was no significant relationship between the development of motility restrictions and whether the macula was attached on presentation.

\section{Stereopsis}

No relationship was demonstrated between the level of stereopsis as measured by Frisby plates and the presence of diplopia.

\section{Considering Radial and Circumferential Elements Separately}

Forty per cent (4/10) of radial and 67\% (39/58) of circumferential explants caused some restriction of eye movements. Fisher's exact test shows that this approaches significance $(p=0.075)$. The 2 eyes with both explants are excluded.

Sixty per cent of patients with radial plombs and $75 \%$ of patients with circumferential explants had diplopia in the primary position or within their visual field. If we exclude

Table V. The direction in which a restriction of motility was noted in relation to the position of the explant, for circumferential explants only

\begin{tabular}{lccc}
\hline $\begin{array}{l}\text { Restrictions of } \\
\text { gaze }\end{array}$ & $\begin{array}{c}\text { Single } \\
\text { operation }\end{array}$ & $\begin{array}{c}\text { Explant } \\
\text { removed before } \\
\text { review }\end{array}$ & $\begin{array}{c}\text { Explant } \\
\text { changed/ } \\
\text { further surgery }\end{array}$ \\
\hline Away from explant & 11 & 2 & 9 \\
Towards explant & 4 & 0 & 2 \\
Away + towards & 1 & 0 & 2 \\
All directions & 1 & 0 & 1 \\
Unrelated to explant & 3 & 0 & 3 \\
None & 10 & 4 & 5 \\
Totals & 30 & 6 & 22 \\
\hline
\end{tabular}


Table VI. The direction in which diplopia was noted in relation to the position of the explant, for circumferential explants only

\begin{tabular}{lccc}
\hline Diplopia & $\begin{array}{c}\text { Single } \\
\text { operation }\end{array}$ & $\begin{array}{c}\text { Explant } \\
\text { removed before } \\
\text { review }\end{array}$ & $\begin{array}{c}\text { Explant } \\
\text { changed/ } \\
\text { further surgery }\end{array}$ \\
\hline Away from explant & 7 & 1 & 4 \\
Towards explant & 8 & 1 & 3 \\
Away + towards & 0 & 1 & 1 \\
$\begin{array}{l}\text { One or two directions } \\
\quad\left(360^{\circ} \text { explant) }\right.\end{array}$ & 1 & 0 & 2 \\
$\begin{array}{l}\text { All directions } \\
\quad\left(360^{\circ} \text { explant) }\right.\end{array}$ & 0 & 0 & 1 \\
$\begin{array}{l}\text { Unrelated to explant } \\
\text { Primary position }\end{array}$ & 2 & 1 & 2 \\
None & 1 & 0 & 2 \\
None, as poor VA & 1 & 2 & 2 \\
Totals & 30 & 0 & 3 \\
\hline
\end{tabular}

those with poor acuity this decreases to $73 \%(38 / 52)$. Fisher's exact test shows no significant difference $(p=0.20)$. Only $20 \%(2 / 10)$ of patients with radial plombs and $10 \%(6 / 58)$ of those with circumferential explants had no abnormality to find on examination. The 2 eyes with both explants had motility abnormalities.

Tables V and VI show the motility restrictions and diplopia for the circumferential explants alone. For circumferential explants $84 \%$ of restrictions and $87 \%$ of diplopia seen are related to the position of the explant. For radial sponges $75 \%$ of restrictions and $83 \%$ of diplopia seen are related to the position of the explant; these latter figures are based on a small sample. There is no significant difference between these two groups (Fisher's exact test $p=0.40$ and $p=0.42$ ).

\section{Second Operation}

From Tables III and IV it is apparent that there is a greater incidence of motility problems if the patient has a second procedure. Diplopia within the field tested for BSV is significantly more likely after a second detachment procedure than a first operation (chi-squared analysis, $p=0.0297$ ). Patients with acuity too poor to perform a field of BSV were excluded from the analysis but all explants were included. If the patients in whom the explant was removed at a second operation are included with those who have only one procedure the statistical significance remains ( $p=0.0297$ ).

Restricted motility after further detachment surgery is more common than after a simple procedure but not at a statistically significant level $(p=0.1139)$. However, if those patients who have their explant removed are considered with those who have one detachment procedure then this still does not achieve statistical significance $(p=0.0605)$.

\section{DISCUSSION}

The incidence of post-operative strabismus reported has varied considerably between studies. ${ }^{1-18}$ Retrospective analysis of several case records by some authors ${ }^{4.5 .11}$ has yielded a low incidence whilst other authors have calculated the incidence from the number of patients referred to the orthoptic department for assessment. ${ }^{7,10}$ From our results it is evident that this detects only the majority of the patients with clinically significant strabismus since some of our symptomatic patients were not documented as having problems. This approach does not demonstrate the true incidence of ocular motility abnormalities induced by retinal detachment surgery. One previous study by Smiddy et al. ${ }^{19}$ found that $73 \%$ of their patients had some limitation of ductions on ocular examination. However, many of their patients were treated by encirclement, a technique previously noted to be associated with motility problems $^{5.9}$ but not performed routinely in our unit. Seventy-two per cent of the patients in our study who were treated by circumferential segmental explants or radial plombs had diplopia within their tested field of BSV and $65 \%$ of eyes had some restriction of ocular motility. Only $12 \%$ of patients showed no abnormality on examination.

Other authors have suggested that post-operative strabismus is temporary. ${ }^{5.16}$ Smiddy et al..$^{19}$ showed that it was a persistent problem. They reviewed patients at 3-6 weeks and found that by the final examination at 4-22 months (median 6 months) 26\% had improved but 36\% had deteriorated. Our results, with longer follow-up (median 22 months), show a similar proportion of patients with restrictions and confirm that these motility defects are a longterm complication of scleral buckling surgery.

Smiddy et al..$^{19}$ considered that the ocular motility restrictions found in their study were not usually clinically significant, although we note that $18 \%$ had acquired a primary position tropia. We found that 10 patients (15\%) with no pre-operative history of strabismus or amblyopia developed primary position tropias; however, some of these were asymptomatic because of poor vision or suppression of the second image. Others with less significant motility defects had 'mild symptoms' which were attributable to their explant, e.g. diplopia in a secondary position of gaze which could prevent them from driving or performing tasks at work. We consider it significant that $39 \%$ had a vertical phoria of $>2$ dioptres and $7 \%>5$ dioptres, which would be expected to contribute to asthenopic symptoms.

Previous studies have attempted to correlate the size and site of the explant with the presence of a motility problem. Different explants and buckles used and different surgical techniques have led to differing results. Sewell $e t$ al. ${ }^{15}$ in 1974 found that a significantly greater number of patients had muscle imbalance if a large volume of silicone material was placed beneath one or more of the rectus muscles. They considered a large explant to be a Mira 276, 277 or 279 circumferential explant or an $8 \mathrm{~mm}$ sponge. Small implants included smaller sponges, encircling bands and preserved sclera. Smiddy et al. ${ }^{19}$ showed that post-operative strabismus was significantly associated with encirclement. Our results confirm that a larger buckle is significantly associated with greater restriction of motility. We have demonstrated for the first time that the more muscles the explant is placed under the more directions of gaze are likely to be restricted. 
Considering the association between explant position and direction of motility disturbance, Sewell et al. ${ }^{15}$ showed a correlation between the placement of the explant under a rectus muscle and 'muscle imbalance' but no correlation with the direction. Tenotomy of an extraocular muscle was not significantly associated with the development of muscle imbalance. Other studies have found no correlation between the motility defect produced and the placement of an explant under the corresponding rectus muscle or its antagonists. ${ }^{19}$ Kanski et al. ${ }^{5}$ suggested that a plomb placed below a muscle could lead to its overaction (by displacement of the muscle) and that paresis (or underaction) could be caused by scleral resection. In their study 25 of 30 patients with diplopia had had a muscle detached during surgery. They concluded, like Norton, ${ }^{20}$ that detachment of the recti should not be performed routinely in retinal detachment surgery because of the risks of causing diplopia. None of our patients had detachment of an extraocular muscle. It is therefore interesting that for $84 \%$ of those with some restriction and for $87 \%$ of those with some diplopia the motility defect correlates with the site of the explant. The correlation of the deficit in our patients with the site of the explant may have been demonstrable because none of the eyes were encircled (unlike those in previous studies) and because the majority of the patients had segmental circumferential explants directly related to the recti. In our patients restriction was more likely to be in the direction away from the buckle, suggesting tethering of the muscle. Less frequently it was towards the explant, suggesting there may be a mechanical limitation of movement. Diplopia was more likely to be experienced towards the explant, perhaps indicating the reduced action of the muscle. In some patients the explant was overlying the inferior or superior oblique muscle and this appeared to cause these muscles to be underactive. Unlike some authors ${ }^{5,10}$ we did not find this to be a frequent cause of diplopia.

Our findings would be consistent with Romaine's ${ }^{1,3}$ suggestions that the major causes of muscle imbalance are (1) adhesions between the globe and the muscle and/or conjunctiva causing muscle restriction, (2) a bulk effect of the buckle under a muscle altering its action and (3) direct muscle injury. He commented that traction on a muscle with a bridle suture may be as traumatic as disinserting the muscle. These mechanisms are confirmed by other authors. Portney et al. ${ }^{11}$ showed in rabbit studies that manipulation of the muscle alone caused adhesion to the globe. Restrictive fibrosis has been shown to occur in all types of retinal surgery, including cryotherapy alone..$^{2,21}$ Bell and Pruet ${ }^{22}$ showed that cryotherapy causes histological changes in extraocular muscles in animal studies. Dunlap $^{23}$ attempted to shield the muscle locally but was unable to prevent fibrosis. This highlights the importance of careful surgical technique to minimise trauma to the extraocular muscles and Tenon's capsule.

We found a tendency for circumferential scleral buckles to be associated with a higher incidence of motility disturbance than radial plombs, although not with more clinically significant problems.
There was a significantly greater incidence of problems in patients who had undergone more than one retinal detachment procedure. This has been noted previously ${ }^{9,17}$ but only demonstrated to be significant by Sewell et al. ${ }^{15}$ We found that a second procedure to remove the explant does not appear to cause a motility defect. In our patients this was done for extrusion of the explant except in 1 patient with diplopia. Most authors ${ }^{4.17}$ agree that removal of a plomb for strabismus may not lead to resolution of the symptoms, although it appears to be a logical first step and this was the case for our patient.

In our study there was a correlation between poor visual acuity pre-operatively, i.e. detachment of the macula, and the development of a motility disorder. Our patients with a 'macula on' detachment were significantly more likely to develop diplopia within their expected field of BSV, presumably because of their good acuity. This contradicts the findings of Sewell et al. ${ }^{15}$ but it should be remembered that the groups are not directly comparable due to changes in surgical techniques over the 20 years separating the results.

Our study demonstrates a high rate of persistent ocular motility abnormalities after conventional scleral buckling surgery using predominantly circumferential silicone tyres. In view of the morbidity caused by these procedures it should be considered whether greater use of internal tamponade is indicated for patients, particularly those at risk of diplopia, i.e. the 'macula on' detachments. Pneumatic retinopexy has been shown to be equally successful in achieving re-attachment of rhegmatogenous retinal detachment but is associated with other complications including new retinal break formation. ${ }^{24}$ In the light of our results and others summarised in this report, greater use of primary vitrectomy and internal tamponade might be considered. A prospective study comparing ocular motility problems following internal tamponade with those resulting from conventional scleral buckling surgery is required.

Key words: Diplopia; Ocular motility disorders, Retinal detachment surgery, Surgical complications.

\section{REFERENCES}

1. Amemiya T, Yoshida H, Harayama K, Miki M, Koizumi K. Long-term results of retinal detachment surgery. Ophthalmologica 1978;177:64-9.

2. Arruga A. Motility disturbances induced by operations for retinal detachment. Mod Probl Ophthalmol 1977;18: 408-14.

3. Arruga A. Binocularity after retinal detachment surgery. Doc Ophthalmol 1973;34:41-5.

4. Fison PN, Chignell AH. Diplopia after retinal detachment surgery. Br J Ophthalmol 1987;71:521-5.

5. Kanski JJ, Elkington AR, Davies MS. Diplopia after retinal detachment surgery. Am J Ophthalmol 1973;76:38-40.

6. Kutschera $\mathrm{E}$, Antlanger $\mathrm{H}$. Influence of retinal detachment surgery on eye motility and binocularity. Mod Probl Ophthalmol 1979;20:354-8.

7. Maillette de Buy Wenniger-Prick L, van Mourik-Noordenbos A. Diplopia after retinal detachment surgery. Doc Ophthalmol 1988;70:237-42. 
8. Mets MB, Wendell ME, Gieser RG. Ocular deviation after retinal detachment surgery. Am J Ophthalmol 1985;99: 667-72.

9. Pearlman JT, Christensen RE. Motility problems following retinal detachment surgery. Am Orthop J 1972;22:64-7.

10. Peduzzi M, Campos EC, Guerrieri F. Disturbances of ocular motility after retinal detachment surgery. Doc Ophthalmol 1984;58:115-8.

11. Portney GL, Campbell LH, Casebeer JC. Acquired heterotropia following surgery for retinal detachment. Am J Ophthalmol 1972;73:985-90.

12. Price RL, Pederzolli A. Strabismus following retinal detachment surgery. Am Orthop J 1982;32:9-17.

13. Romaine HH. Motility complications in buckling procedures. Trans Am Acad Ophthalmol Otolaryngol 1961;65: 718-23.

14. Roth AM, Sypnicki BA. Motility dysfunction following surgery for retinal detachment. Am Orthop J 1975;25:118-21.

15. Sewell JJ, Knobloch WH, Eifrig DE. Extraocular muscle imbalance after surgical treatment for retinal detachment. Am J Ophthalmol 1974;78:321-3.

16. Theodossiadis G, Nikolakis S, Apostolopoulos M. Immedi- ate post-operative muscular disturbance in retinal detachment surgery. Mod Probl Ophthalmol 1979;20:367-72.

17. Waddell E. Retinal detachment and orthoptics. Br Orthop J 1983;40:5-12.

18. Wolff SM. Strabismus after retinal detachment surgery. Trans Am Ophthalmol Soc 1983;81:182-92.

19. Smiddy WE, Loupe D, Michels RG et al. Extraocular muscle imbalance after scleral buckling surgery. Ophthalmology 1989;96:1585-9.

20. Norton EWD. Complications of retinal detachment surgery. Transactions of the New Orleans Academy of Ophthalmology. St Louis: CV Mosby, 1969:222.

21 . Wright $K$. The fat adherence syndrome and strabismus after retina surgery. Ophthalmology 1986;93:411-5.

22. Bell FC, Pruett RC. Effects of cryotherapy on extraocular muscle. Ophthalmic Surg 1977;8:71-5.

23. Dunlap EA. Plastic implants in muscle surgery: plastic materials in the management of extraocular motility restrictions. Arch Ophthalmol 1968;80:249-57.

24. Tornambe PE, Hilton GF, Brinton DA et al. Pneumatic retinopexy: a 2 year follow-up study of the multicentre clinical trial comparing pneumatic retinopexy with scleral buckling. Ophthalmology 1991;98:1115-23. 